\title{
ESTUDO DE CASO DE IMPLANTAÇÃO DO PRONTUÁRIO ELETRÔNICO DO PACIENTE, EM UM HOSPITAL ESCOLA
}

\author{
Cleyton Alves da Mota ${ }^{1}$ \\ Ney Cândido da Silva Ribeiro²
}

Resumo: Este artigo trata sobre um estudo de caso entre dois sistemas, o prontuário manual do paciente $(P M P)$ e o prontuário eletrônico do paciente $(P E P)$ na área da saúde. Esta pesquisa irá visar um estudo comparativo entre os dois sistemas, através de cronoánalise para buscar resultados através de dados estatísticos, e desta forma apontar qual dos sistemas é mais eficiente ou eficaz para a empresa. Pretendese com este estudo provar ou demonstrar que o prontuário eletrônico do paciente é mais eficiente que o prontuário manual em vários sentidos, desde a sua facilidade em manuseio onde qualquer profissional da área da saúde consiga manipular as suas informações de maneira segura, confiável e de fácil entendimento. Palavras-chave: PEP; PMP; Saúde; Confiável; Segura; Facilidade.

1 Sistemas de Informação, Centro Universitário de Itajubá - FEPI, Brasil, E-mail: tecinfcleytinho07@yahoo.com.br.

2 Sistemas de Informação, Centro Universitário de Itajubá - FEPI, Brasil, E-mail: ney.candido.ribeiro@gmail.com. 